\title{
The Hong Kong parking demand study
}

\author{
W. C. H. Lam, BSc, MSc, CEng, MICE, MHKIE, MCIT, R. Y. C. Fung, BSc, \\ MHKIE, S. C. Wong, BSc, MPhil, PhD, MIHT, MITE, MCIT, MASCE and \\ C. O. Tong, BSc, PhD, CEng, MICE, MHKIE
}

- This paper describes the objectives, methodology, findings, recommendations and implementation programme of a parking demand study which was conducted in Hong Kong during the period 1993-1995. The study comprises extensive surveys to establish parking characteristics and parking inventory, a stated preference survey to estimate the influence of parking space availability on modal choice, development of parking demand models for private cars and goods vehicles, identification of problems related to parking, and formulation of remedial measures.

Keywords: roads \& highways; traffic engineering; transport planning

\section{Introduction}

The city of Hong Kong, depicted in Fig. 1, consists of three main districts: Hong Kong Island, Kowloon, and the New Territories. During Hong Kong's early development as an entrepôt, the city centre was established in a place called Victoria, located on the northern shore of Hong Kong Island. As the island is very hilly, development spread sideways along the coast rather than inland. Hong Kong Island north now contains the Central business district (CBD) as well as residential districts and shopping centres. In contrast, Hong Kong Island south is a scenic area with many beaches. Being separated from the north by a mountain ridge, the south was developed mainly for low density housing, and for recreation.

2. On the southern tip of Kowloon peninsula is a tourist centre with an ocean terminal, a cultural complex, hotels and shopping centres. Other parts of Kowloon are residential and industrial districts.

3. The New Territories comprise two parts: the first part is an area located north of Kowloon and connected to the mainland; the second part consists of many outlying islands, the largest of which is Lantau Island. New Territories mainland was a rural district with farmlands and fishponds, but is now mostly urbanized with the development of several new towns and a container port. Lantau Island is still largely uninhabited, but will soon be urbanized rapidly because of the recent completion of a highway and a railway and a new airport.
4. Hong Kong is a crowded city with $6 \cdot 5$ million people living in a land area of 1100 sq. $\mathrm{km} .{ }^{1}$ At the end of 1995, it had 466000 licensed vehicles and only $1541 \mathrm{~km}$ of roads. ${ }^{2}$ Since Hong Kong is an important finance and shipping centre in the Asia Pacific Region, its economic performance relies heavily on an efficient transportation system. Hence, the Government has placed a high priority on studying how to use the road network effectively and how to relieve congestion on the roads. ${ }^{3,4}$

5. During the last decade, apart from a substantial increase in the number of private vehicles, Hong Kong's container port also expanded rapidly, and as a result, over one quarter of the city's vehicle fleet is goods vehicles. ${ }^{1}$ The provision and management of parking spaces and loading/unloading facilities for this large number of goods vehicles has become an urgent issue that requires detailed consideration.

6. Parking provision could be an effective means to control the use of the private car, particularly for the trip to work. However, in an area with a severe shortage of parking spaces, illegal parking and waiting on the roads would cause road congestion. Space must also be provided for loading/unloading of goods and picking-up/setting-down of passengers. It is therefore necessary to strike a balance between parking supply and the capacity of the road system in the planning of parking facilities.

7. Various transportation surveys and studies, such as the travel characteristics survey ${ }^{5}$ and the freight transport study, ${ }^{6}$ had collected information relating to parking provision and use of parking facilities. There was, however, neither a comprehensive parking inventory covering the whole city, nor an assessment of future parking supply and demand in different districts. There was no detailed study of how parking provision and charges might affect traveller behaviour. Without comprehensive information, it was not possible for the Government to formulate appropriate parking policies.

8. Against this background, in October 1993, a consortium led by Ove Arup \& Partners was commissioned by the Transport Department to undertake a parking demand study. The study was completed in 26 months and the final report was published in December 1995.
Proc. Instn Civ. Engrs Transp., 1998, 129, Nov., $218-227$

Paper 11780

Written discussion closes 15 May 1999

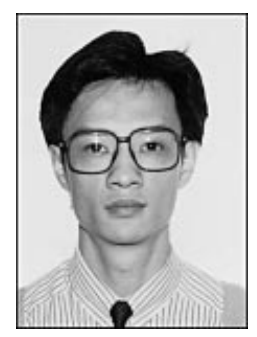

Wilkie C. H. Lam, Director, LLA Consultancy Ltd (formerly Head of Arup (HK)

Transportation

Group), Hong Kong

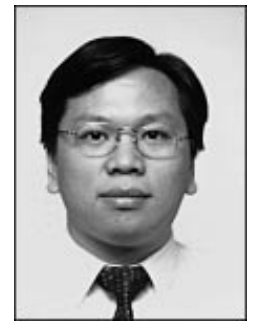

Rayson Y. C. Fung, Engineer, Transport Department, The Government of Hong Kong SAR (formerly Engineer, Arup (HK) Transportation Group), Hong Kong

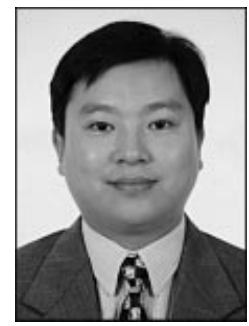

S. C. Wong,

Lecturer, Department of Civil Engineering, The University of Hong Kong 


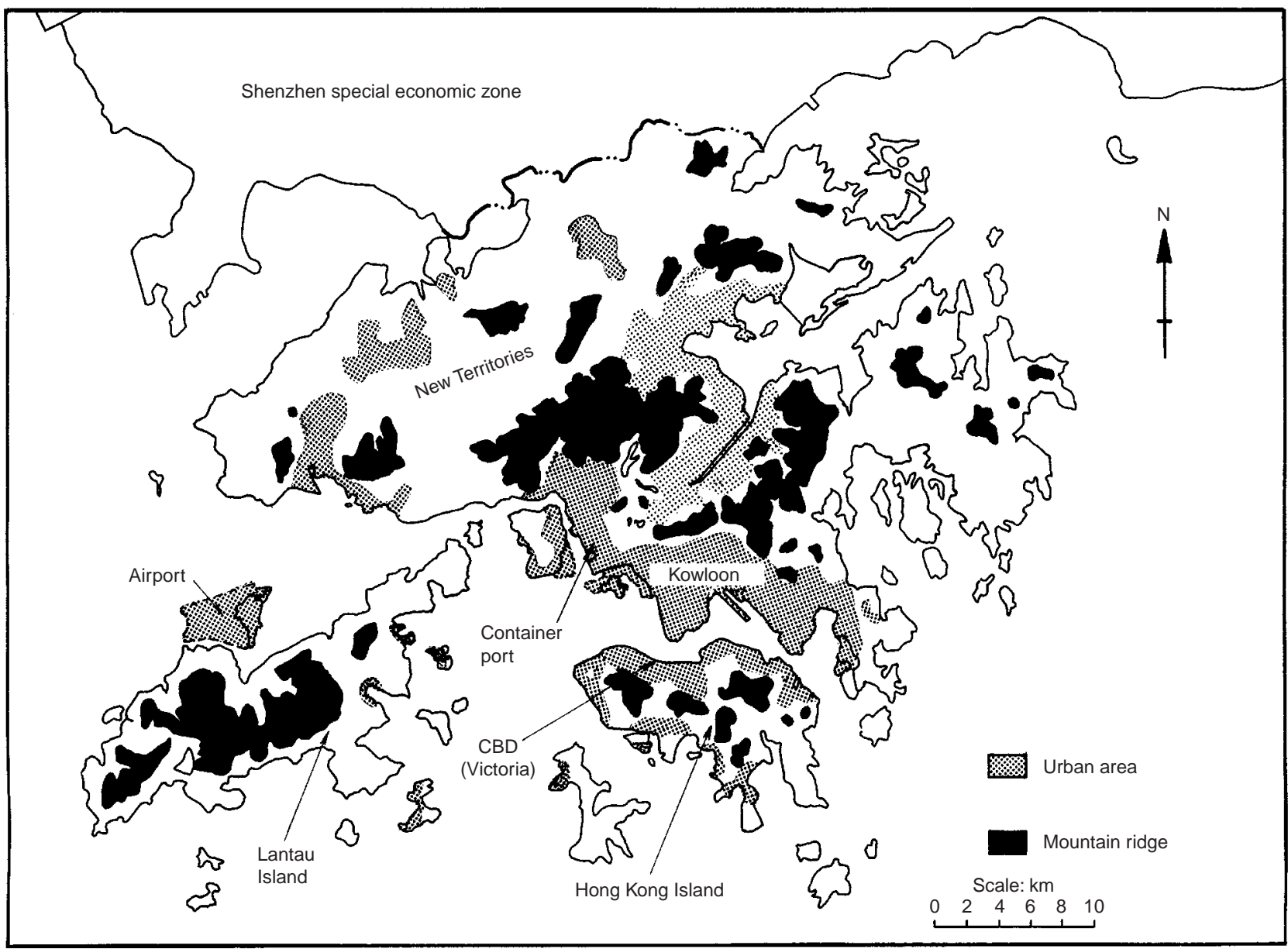

9. The objectives of the study were to

(a) prepare a comprehensive and territorywide parking inventory

(b) develop a parking demand model

(c) identify districts with existing/future shortfall in parking facilities

(d) review the Hong Kong Planning Standards and Guidelines relating to parking provi$\operatorname{sion}^{8}$

(e) recommend solutions to problems identified by the study

$(f)$ demonstrate how the recommendations could be implemented.

10. This paper presents an outline of the study. The following sections describe: the parking inventory survey, the parking characteristics survey and the stated preference survey; the development of the parking demand models; the recommendations; the implementation programme; the conclusions.

\section{The Surveys}

\section{Parking inventory survey}

11. In Hong Kong, off-street parking spaces are either publicly or privately owned. As a result, inventory information on parking spaces is scattered, incomplete and often outdated. The parking demand study aims to build a comprehensive parking inventory database for onstreet and off-street parking spaces as well as loading/unloading facilities for the whole city with the exception of the outlying islands.

12. The data collection exercise involved compilation of existing data available from a number of government departments, including the Rating and Valuation Department, Lands Department, Buildings Department, as well as other bodies, such as Hong Kong Housing Authority and Hong Kong Housing Society. In addition, extensive questionnaire surveys and physical counts were carried out. Data were collected on the location and attributes of car parking spaces such as parking space by different vehicle types, fare structure and time of operation. For off-street car parks, information on development type/mix and gross floor area were also collected. The following parking inventories were compiled
(a) off-street parking inventory
(b) on-street parking inventory
(c) off-street loading/unloading inventory
(d) on-street loading/unloading inventory.

13. In the first quarter of 1994, there were approximately 458000 parking and loading/ unloading spaces, of which 432000 were off-
Fig. 1. The city of Hong Kong

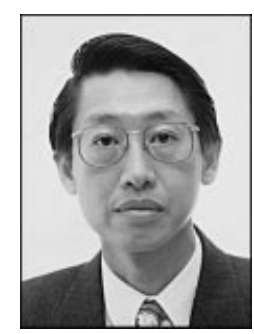

C. O. Tong, Associate Professor, Department of Civil Engineering, The University of Hong Kong 
street spaces and 26000 were on-street spaces. The parking and loading/unloading supply for off-street and on-street facilities by vehicle types for the whole territory are depicted in Fig. 2.

\section{Characteristics survey}

14. The parking characteristics survey aims to provide information for the development of the parking demand model and for the review of the Hong Kong Planning Standards and Guidelines. ${ }^{8}$ The latter is a government manual setting out the criteria and guidelines for various types of urban developments. The survey was concentrated on sites dominated by usage-related parking demand, such as retail, office, industrial and hotel developments.

15. The survey covered a total of 227 offstreet sites (which are representative of different land-use types) as well as 42 locations providing on-street parking spaces (metered and non-metered). The survey involved observation of parking and loading/unloading activities generated for each land-use type, generally over a 16-hour time period. At off-street car parks, registration number-plate surveys were carried out to determine parking duration and parking accumulation. For car parks at mixed land-use developments, for example offices and shops, interviews were carried out to ascertain the trip purpose of each parked car.

16. The parking accumulation thus established from the survey permitted the expected number of parked vehicles, or parking demand, to be estimated, provided that the number of trip-ends associated with the land-use development in question is known. Total trip-ends for each land-use were derived from the second comprehensive transport study (CTS-2) demand model. ${ }^{9}$ In the present study, these relationships are depicted as 'unitgraphs' and the following four categories of unitgraph were developed

(a) private car off-street

(b) on-street (metered and non-metered)

(c) goods vehicle off-street

(d) goods vehicle on-street.

17. To illustrate the unitgraph concept, a typical shopping centre, the Kowloon City Plaza, is chosen here as an example. First, from the survey results, the daily accumulation profile is considered. To determine the unitgraph, the profile is then divided by the total trip-ends at the site. The results are illustrated in Fig. 3.

18. The average dwell times for different vehicle types and time of day for on-street activities are shown in Table 1. From the table, it is seen that private car on-street dwell time in the evening peak is longer than in the morning peak. This is because set-down activities pre-

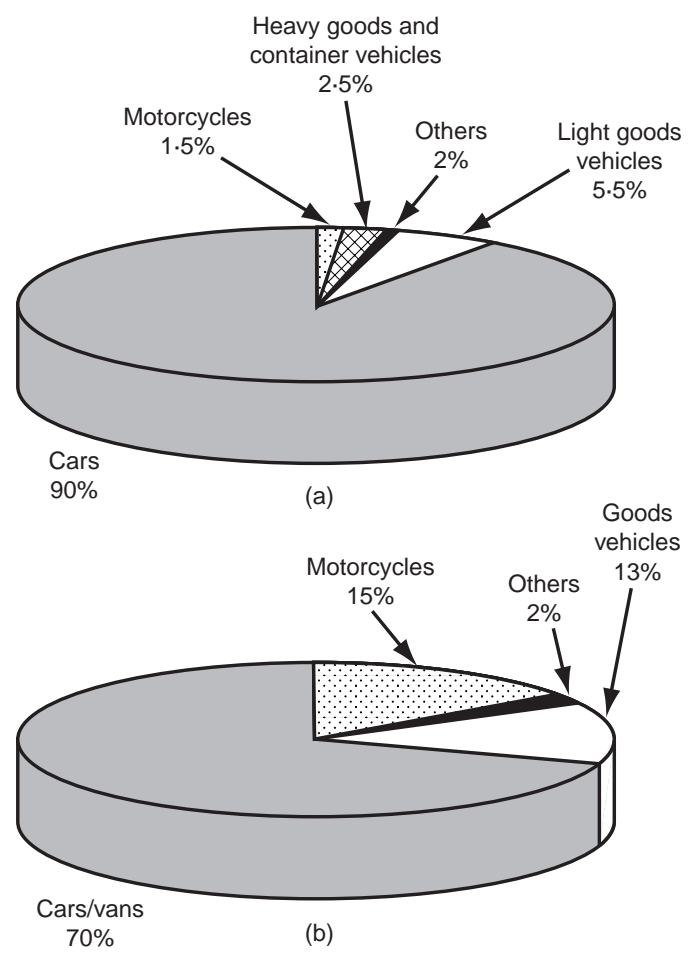

Fig. 2. Pie charts showing: (a) off-street parking and loading/ unloading supply 1994; and (b) on street parking supply 1994

dominate in the morning whereas pick-up activities (which usually take a longer time) predominate in the evening. Depending on the time of day, passenger pick-up/set-down generally takes no longer than 1 or 2 min on average and even for coaches is only about 5$6 \mathrm{~min}$ on average. However, goods vehicles take

Fig. 3. Accumulation profile and unitgraph for Kowloon City Plaza

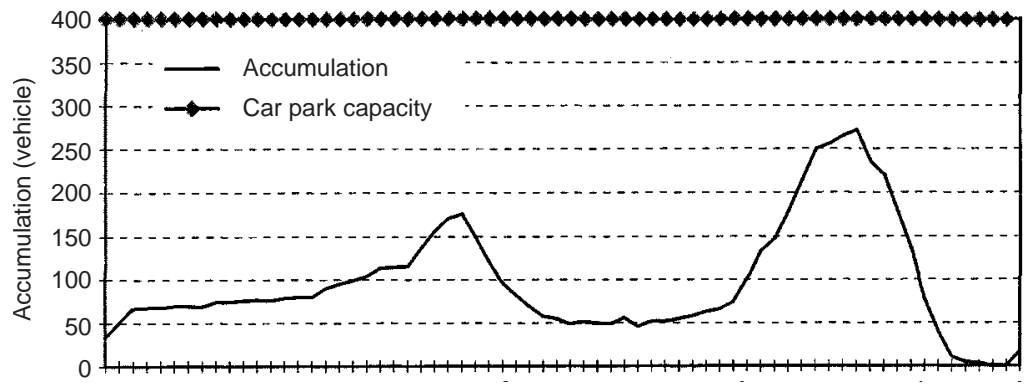

(a)

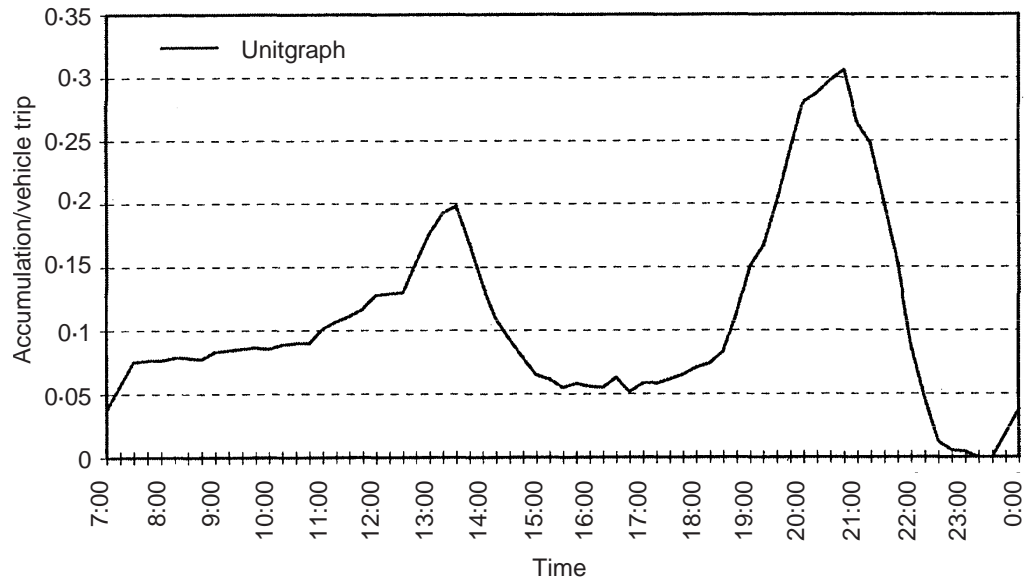

(b) 
up a much longer dwell time for loading/ unloading.

19. The characteristics of loading/unloading activities for goods vehicles are further illustrated in Table 2, which shows that for all land-use types, a large proportion of loading/ unloading was carried out by light goods vehicles (goods vehicles of less than $7-8 \mathrm{~m}$ in length). These results reflect the nature of the current goods vehicle fleet and also the predominance of small shops requiring delivery of small quantities of goods.

\section{Stated preference survey}

20. The stated preference survey aims to investigate the behaviour of car-owning households. This survey technique was selected in order to investigate the impacts of attitudinal and qualitative parameters on parking behaviour and also to test the respondents' preferences when facing hypothetical situations. ${ }^{10}$

21. In the pilot survey, three factors were found to have large influences on parking choice behaviour

(a) the parking space search time

(b) how much the respondents were willing to pay for parking

(c) how long they would be prepared to walk/ wait if they were to travel by public transport.

The main survey would be designed to determine the factors that influence the motorist's decision to drive, and in turn the potential parking demand.

22. In the main survey, stratified samples were taken from car-owning households residing in four different types of residential density zones based on development density: R1, R2, R3 and R4. (R1 has the highest density whereas R4 the lowest.) Within each density class, households were further subdivided into rail and nonrail accessible groups, depending on their proximity to rail-based transport. A total of 625 successful interviews were conducted and random logic checks were performed on three out of every ten completed surveys to verify responses.

23. The respondents were asked about the main reasons for not using the private car for a variety of destination land-uses. From the survey data, it was found that, in addition to land-uses, the main tangible parameters that could have a great influence on modal choice were parking availability, public transport accessibility and parking charges. For the purpose of quantifying the relative impacts of these key parameters, further categorization was undertaken and these are shown in Table 3. In addition, three destination land-use classes, namely shopping centres, industrial areas and residential areas, were introduced.

24. A conjoint model was used to determine
Table 1. Average dwell time-on-street activities by vehicle type (in minutes)

\begin{tabular}{l|c|c|c}
\hline Vehicle type & $\begin{array}{c}\text { a.m. peak } \\
\text { 07:00-10:00 }\end{array}$ & $\begin{array}{c}\text { p.m. peak } \\
16: 00-19: 00\end{array}$ & Off-peak \\
\hline Private car & $1 \cdot 0$ & $2 \cdot 3$ & $1 \cdot 9$ \\
Taxi & $0 \cdot 7$ & $0 \cdot 9$ & $1 \cdot 1$ \\
Coach & $6 \cdot 0$ & $4 \cdot 8$ & $4 \cdot 5$ \\
Van & $11 \cdot 2$ & $9 \cdot 9$ & $10 \cdot 5$ \\
Light goods vehicle & $18 \cdot 6$ & $13 \cdot 6$ & $17 \cdot 2$ \\
Heavy goods vehicle & $18 \cdot 3$ & $10 \cdot 7$ & $18 \cdot 7$ \\
\hline
\end{tabular}

Table 2. Proportion of goods vehicles loading/unloading by size and land-use

\begin{tabular}{l|c|c}
\hline Land-use & \%LGV: $<7-8 \mathrm{~m}$ length & \%HGV: $>7-8 \mathrm{~m}$ length \\
\hline Retail & 98 & 2 \\
Office & 91 & 9 \\
Industrial & 86 & 14 \\
Hotel & 100 & 0 \\
Residential & 92 & 8 \\
\hline
\end{tabular}

LGV: light goods vehicles

HGV: heavy goods vehicles

Table 3. Stated preference-scenario levels

\begin{tabular}{l|c|c|c}
\hline Description & Good & Medium & Poor \\
\hline $\begin{array}{l}\text { Public transport accessibility } \\
\text { (mean walking + waiting time } \\
\text { in minutes) }\end{array}$ & 11 & 17 & $25 \cdot 2$ \\
Parking charges (HK\$/h) & $9 \cdot 1$ & 14 & 20 \\
$\begin{array}{l}\text { Parking availability } \\
\text { (mean waiting time in minutes) }\end{array}$ & $7 \cdot 8$ & 14 & 22 \\
\hline
\end{tabular}

the relative importance of various model parameters. In the survey, respondents were asked to indicate their preferences (ratings) for a selected subset of all the possible combinations of the four parameters, and the three levels set for each parameter. The subset was selected so that the ranking of those scenarios not presented could be calculated together with those that were. The model also calculated the relative value of each level of each parameter within a combination so that assessments of both the importance and contribution of each to the particular decision taken could be made. The resultant utility values are presented in Table 4.

25. The difference between the highest and lowest score shows how important the particular parameter is in the decision-making process. When it is large, it is more important, as reflected by its greater contribution to the total score. When it is low, the other three factors would then have a greater impact. Therefore, the results show that the more important parameters influencing modal choice are 'destination land-use type' and 'parking availability'. For the other two factors, only high parking 
charges and/or good public transport availability would have a significant effect on modal choice.

26. It is very likely that the parameter 'destination land-use' is correlated with the other parameter 'parking availability'. The provision of visitor car parks at residential buildings generally depends on the density zoning. Visitor parking is usually available at shopping centres and not usually available at industrial buildings.

27. While high parking charges are a deterrent, the small difference between medium and low parking charges indicates a limited influence over the decision to drive.

28. The strongest influence on the decision to drive is parking availability, and therefore reducing the supply of parking spaces could significantly increase people's decision not to drive to that particular location. In general, the results of the conjoint analysis could be used to experiment with different scenarios for managing parking demand. In addition, the results were taken into consideration when considering the effectiveness of general solutions for managing parking demand.

\section{Parking demand models}

29. The study aims to develop a model capable of forecasting future demand for parking and loading/unloading facilities by vehicle type and to the level of the zones used in CTS-2.

30. The following sub-models were developed

(a) private car ownership-related (domestic) demand model

(b) private car usage-related (non-domestic) demand model

(c) goods vehicles usage-related (daytime) demand model

(d) goods vehicles overnight parking demand model.

31. The above sub-models will be integrated with the CTS-2 demand models. This integrated model will be able to forecast the demand for parking and loading/unloading facilities for all zones in the territory, the demand being divided into one or more of the following elements: ownership-related demand, usage-related demand, and suppressed demand. Fig. 4 illustrates the structure of the parking demand model.

32. Ownership-related demand refers to private car domestic parking demand, as well as goods vehicle overnight parking demand. Usage-related demand refers to the daytime trips to facilities, for example, visitors to residential buildings, shoppers to retail centres, etc. Loading/unloading is related to operational or usage-related demand. Suppressed demand refers to trips that would preferably be taken
Table 4. Conjoint model results-weighted utility values

\begin{tabular}{l|c}
\hline Utility & Utility value \\
\hline Destination land-use: & \\
Shopping centre & $0 \cdot 465$ \\
Industrial area & $-1 \cdot 873$ \\
Residential & $1 \cdot 381$ \\
Public transport accessibility: & $-0 \cdot 921$ \\
Good & $0 \cdot 365$ \\
Medium & $0 \cdot 556$ \\
Poor & $0 \cdot 422$ \\
Hourly parking fee: & $0 \cdot 707$ \\
Low & $-1 \cdot 129$ \\
Medium & $1 \cdot 522$ \\
High & $0 \cdot 248$ \\
Availability of parking: & $-1 \cdot 770$ \\
Good & \\
Medium & \\
Poor &
\end{tabular}

by private car but are forced to an alternative mode because of perceived difficulties in parking.

33. From the results of the stated preference survey, it is estimated that in the first quarter of 1994 (the time of survey), on a territory-wide basis, there existed some $20 \%$ of suppressed private vehicle usage-related parking trips.

\section{Private car ownership-related (domestic) demand model}

34. Using the car availability sub-model developed in CTS-2, the level of private car ownership in different zones can be estimated. The model, which takes into account household income, accessibility to employment and supply of residential parking spaces, is considered most appropriate for the forecasting of carownership-related parking demand and was thus adopted for the study.

\section{Private car usage-related (non-domestic) demand model}

35. The structure of the model is presented in Fig. 5. Adopting the latest CTS-2 forecast of private vehicle daily trip-ends as the fundamental input, the first step of the modelling process involved the disaggregation of the tripends into parking and non-parking (pick-up/setdown) trips. The parking trip-ends were then split into home-based trips and non-home-based trips. Trips were paired (e.g. the two trips, from home to work and then from work to home, form a home-based trip pair). In the model, it is assumed than a home-based trip pair would only require one usage-related space whereas a non-home-based trip pair would require two usage-related spaces. The total parking tripends computed were then split by activities, namely on-street meter parking, on-street nonmeter parking, illegal parking and off-street parking. The resulting off-street parking trips 


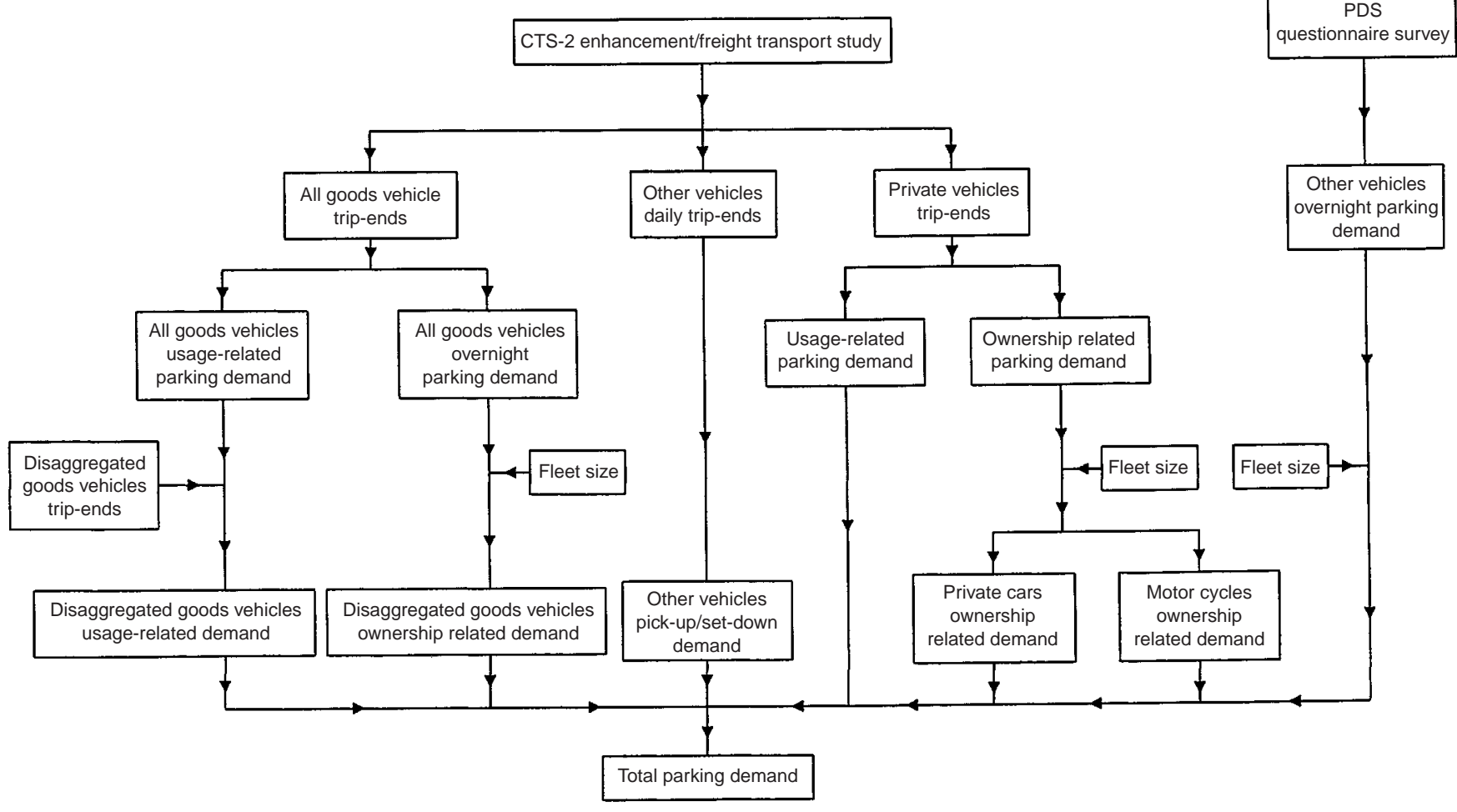

Fig. 4. Structure of the parking demand model

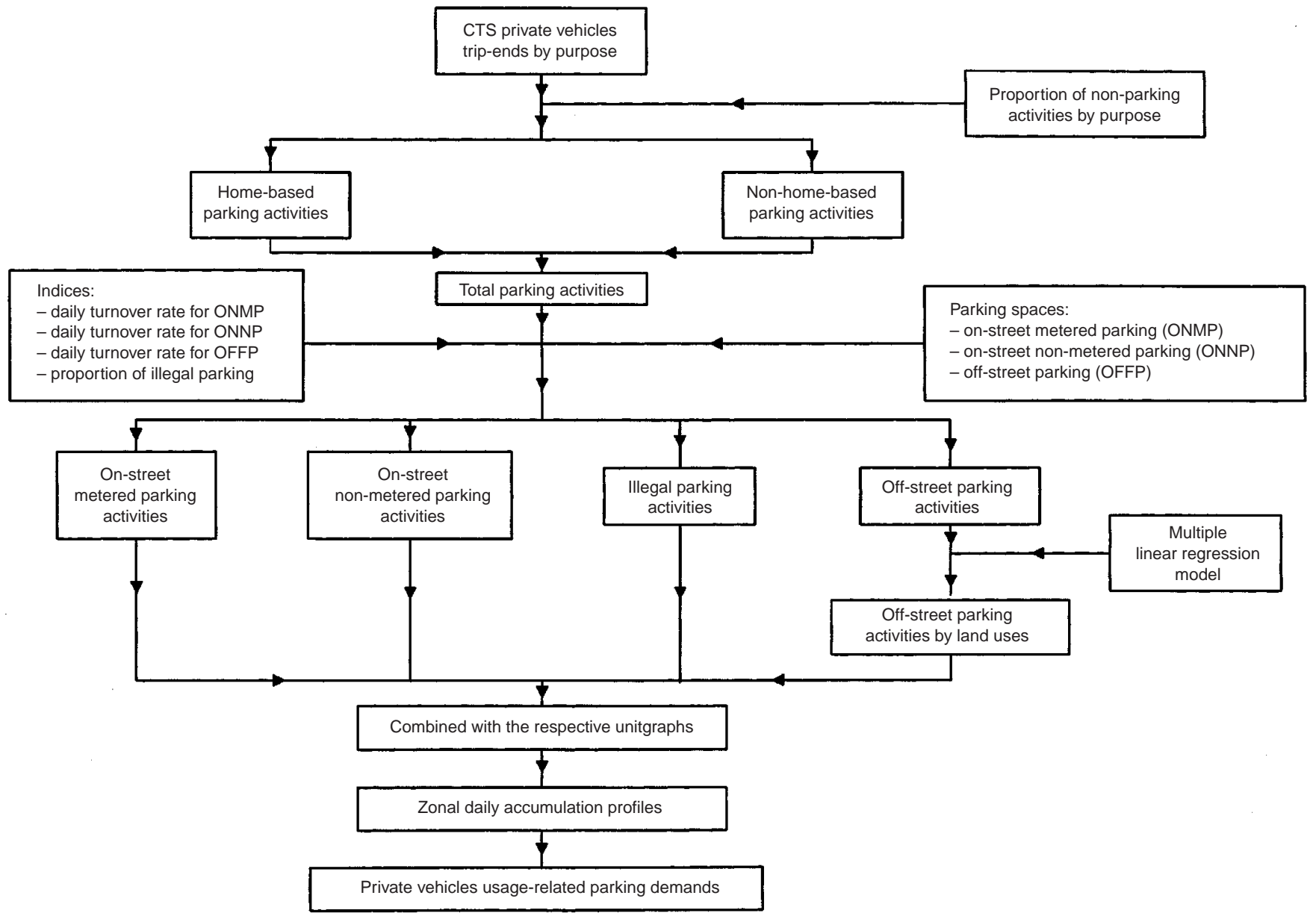

Fig. 5. Private car usage-related demand sub-model 
were then further split by major land-uses through multiple regression analysis. The disaggregated trip-end data were translated into daily accumulation profiles through the mathematical relationships of unitgraphs developed by using the parking characteristics survey data. The individual profiles by land-use and/or parking activities were then combined for the computation of the zonal daily demand profile, from which the peak demand for usage-related facilities could be established.

\section{Goods vehicles usage-related (daytime) demand model}

36. The structure of the model is presented in Fig. 6. The modelling procedure is very similar to that of the corresponding private car model, the fundamental difference being that, for goods vehicles, both parking and loading/ unloading trips have to be considered.

Goods vehicles overnight parking demand model

37. The structure of the model is presented in Fig. 7. From the trip-log records of the freight transport study, the overnight distribution of goods vehicle parking activities was extracted. These data were then correlated with the corresponding land-use parameters by regression analysis. In the model, goods vehicle fleet size was used as a constraining parameter to ensure compatibility.
Assessment of other minor demands

38. The study also considered the demand for the following types of parking activities

(a) private cars' pick-up/set-down requirements

(b) taxis' pick-up/set-down requirements

(c) non-franchised bus pick-up/set-down requirements

(d) goods vehicles on-street loading/unloading requirements

(e) taxis' overnight parking requirements

$(f)$ public light buses' overnight parking requirements

(g) non-franchised buses' overnight parking requirements.

39. The peak hour demand for pick-up/setdown facilities by vehicle types by CTS-2 zones were computed based on

(a) CTS-2 daily trip-end forecast for each particular vehicle type

(b) peak hour factors derived from the Transport Department's Annual Traffic Census ${ }^{2}$

(c) the corresponding average dwell time.

40. The accurate forecasting of future demand for overnight parking facilities for taxis, and public light buses is an extremely difficult, if not impossible task. The demand is influenced by many intangible factors such as migration pattern of drivers, changes in income patterns, and policies influencing the supply of parking facilities. In order to

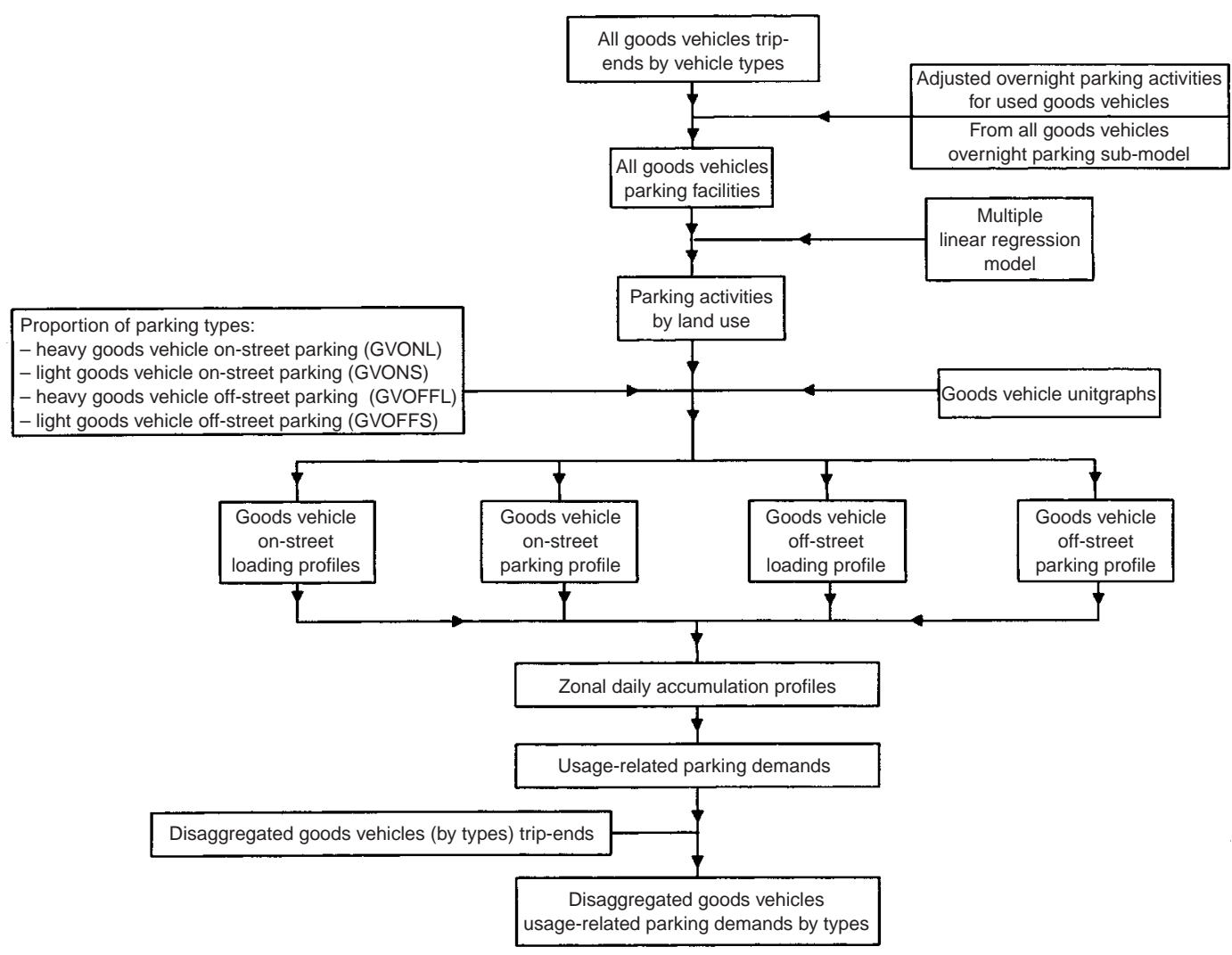

Fig. 6. Goods vehicle usage-related demand (parking and/or loading/unloading) sub-model 


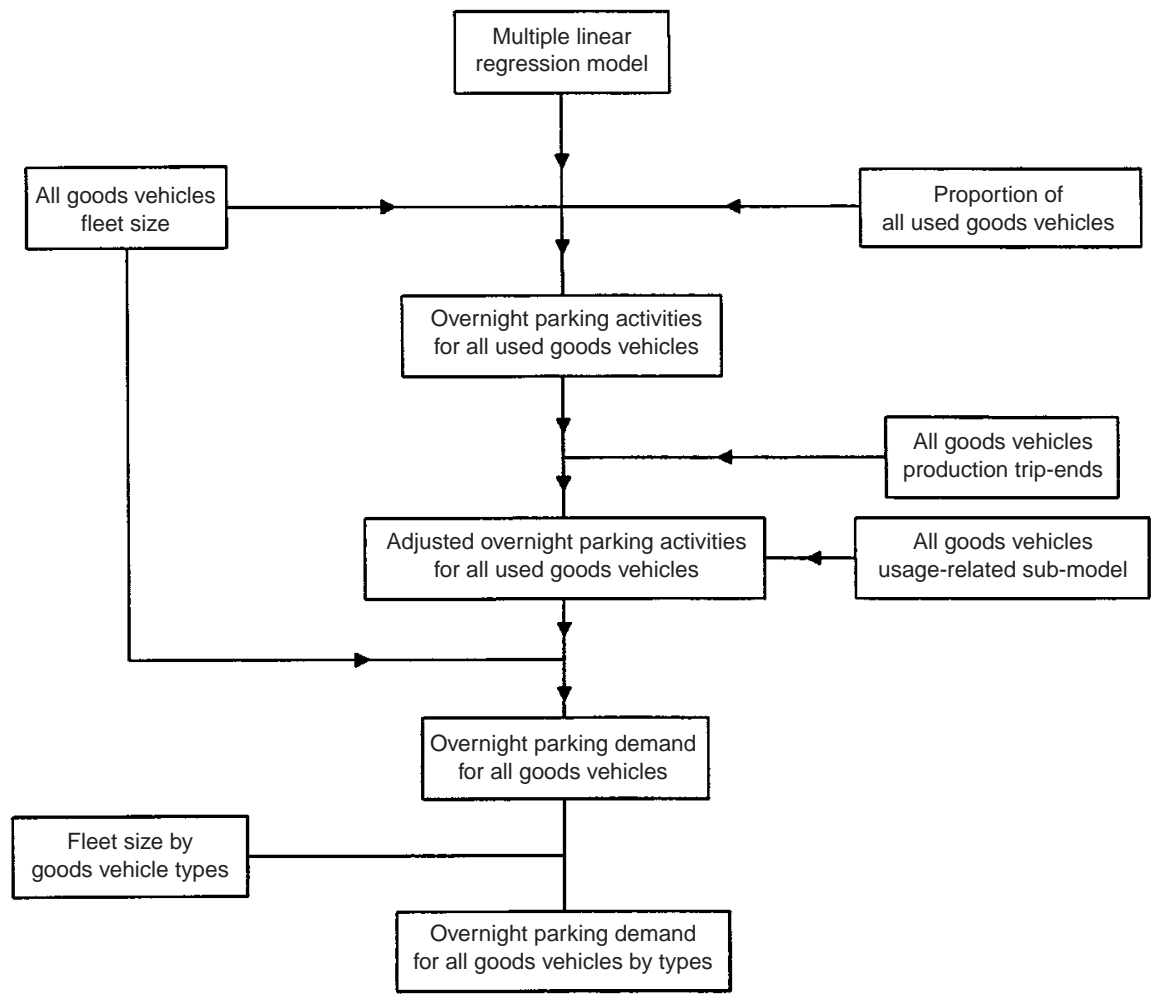

estimate the overnight parking characteristics of these types of vehicle by geographical distribution, a comprehensive questionnaire survey was conducted. Future parking characteristics for these vehicles were then obtained by adjusting the established patterns and taking into account changes in the estimated fleet sizes of these vehicles.

\section{Recommendations}

41. The study found that in 1994 there was a shortfall in parking facilities provision for all types of parking in most districts in Hong Kong. The mismatch was particularly serious for goods vehicle overnight and daytime parking. This section lists the strategies recommended for improving the situation.

42. Four cornerstones of building a plan for improvements were identified in the study

(a) improve planning standards

(b) optimize use of existing facilities

(c) manage demand for facilities

(d) provide additional facilities.

43. Improving planning standards ensures that future developments could accommodate the parking and loading/unloading requirements generated. The study recommends that these new standards be implemented as early as possible. However, as the beneficial effects of these measures would be felt only in the longer term, in the shorter term it is necessary to ensure optimal use of existing facilities and apply demand management techniques.

44. Significant shortfalls in parking and loading/unloading facilities have been identified for goods vehicles, and in some districts for private cars. The most direct way to relieve such problems would be to provide additional facilities. However, as most would involve significant land and financial resources, these measures would require careful planning before implementation.

45. The individual recommendations falling within each of the four cornerstones of the comprehensive plan were as follows.

(a) Improve planning standards

- A1 revision of the Hong Kong Planning Standards and Guidelines.

(b) Optimize use of existing facilities

- A2 on-street overnight parking for goods vehicles

- A3 electronic parking meters

- A4 privatization of enforcement of parking offences

- A5 differential penalties at selected roads and/or areas.

(c) Manage demand for facilities

- A6 kiss and ride

- A7 public transport improvement schemes.

(d) Provide additional facilities

- A8 construction of multi-storey car/ goods vehicle parks

- A9 use of short-term tenancy (SST) sites for parking

- A10 use of landfill sites for goods vehicle parking

- A11 overnight parking for goods
Fig. 7. Goods vehicle overnight parking demand sub-model 
vehicles within existing/future multi-storey car parks

- A12 underground facilities

- A13 development incentives.

46. In addition to the above recommendations, some measures previously identified as suitable for further investigation should be pursued

- B1 provision of container vehicle parking within container terminals

- B2 park and ride

- B3 advance information systems

- B4 mechanical parking systems

- B5 daytime goods vehicle ban.

47. Finally, a number of measures were examined and subsequently discarded as being unsuitable

- C1 wheel clamping

- C2 centralized servicing facilities

- C3 parking tax

- C4 loading/unloading permits

- C5 requirement to possess parking space before ownership of vehicle

- C6 balanced development policy.

\section{Implementation programme}

48. For the implementation of recommendations listed in the previous section, various factors such as planning, design, availability of land and financial resources, institutional arrangements, public consultation and possibly legislative amendments have to be considered. Consequently, some of the recommendations would take a considerable length of time to implement whereas others could be implemented quickly. The study grouped recommended actions into two overall time frames: stage 1 and stage 2 . Actions that were expected to have an impact on the time frame from 1996 to 1998 were classed as stage 1 measures, while those that might not have an immediate impact until 1997 to 2001 were classed as stage 2 measures (see Table 5). However, irrespective of these time frames, the planning for the implementation of all recommendations should be started immediately, given the fact that some of the longer-term measures might take several years for preparation and consultation.

49. Several districts in Hong Kong are experiencing serious parking-related problems with respect to domestic or non-domestic facilities. Ideally, immediate action should be taken to alleviate the problems identified. However, given the extent of the problems, it would not be possible to implement all the necessary measures simultaneously. In view of this, the study gave priority to examining the seriousness of parking problems in various specific districts.

50. In order to take forward and to implement the much-needed measures, a concerted
Table 5. Stage 1 and stage 2 recommended measures

\begin{tabular}{l|c}
\hline Stage & Measures to be implemented* \\
\hline $1(1996-1998)$ & A2, A3, A5, A6, A7, A9 and A10 \\
$2(1997-2001)$ & A1, A4, A8, A11, A12 and A13 \\
\hline
\end{tabular}

*See $\uparrow 45$ for key to numbers.

effort both within and outside the Government is required. The study recognizes the need to administer and to review the recommended measures and develop detailed implementation plans. As with other transport issues, an updating of forecasts at regular intervals is necessary. The effect of the implemented measures should continue to be monitored and the plans revised as and when necessary. The whole exercise would be viewed as a continuing process.

\section{Conclusions}

51. The study has achieved the following major tasks.

(a) By establishing an inventory of parking spaces and loading/unloading facilities, the levels of parking supply in different districts in the city have been ascertained.

(b) A parking demand model has been developed to forecast the future demand for parking facilities in different districts up to the year 2006 .

(c) From the results of $(a)$ and $(b)$, districts which have a large present/future shortfall in parking facilities have been identified.

(d) Revision of parking standards for different types of land uses.

(e) Formulation of specific remedial measures that are tailored and suited to the particular problem identified for specific districts.

( $f$ ) Preparation of an implementation programme for remedial measures.

52. In conclusion, the study recognized an urgent need to take actions to resolve parking problems in Hong Kong. It has formulated a list of remedial measures to alleviate these problems and prepared an implementation pro gramme. However, it must be emphasized that there is now a need to set up a dedicated team which can take the recommendations of the study forward for further investigation and implementation at the district level, and which can also continue to monitor the parking situation in Hong Kong.

\section{Acknowledgement}

53. The Transport Department of the Government of the Hong Kong Special Administrative Region is acknowledged for giving permission to publish a paper based on the work of the parking demand study. 


\section{References}

1. Information Services Department. Hong Kong 1996. Hong Kong Government, 1996.

2. Transport Department. The Annual Traffic Census 1994. TTSD, Hong Kong Government, 1995.

3. Transport Branch. Moving into the Twenty-first Century, the White Paper on Transport Policy in Hong Kong. Government Secretariat, Hong Kong Government, 1990.

4. Transport Branch. Report of the Working Party on Measures to Address Traffic Congestion. Unpublished Report, Hong Kong Government, 1994.

5. MVA Asia. Travel Characteristics Survey-Final Report. Territory Transport Planning Division, Transport Department, Hong Kong Government, 1993.

6. Transport Department with Scott Wilson
KIRKPATRICK. Freight Transport Study-Final Report. Territory Transport Planning Division, Transport Department, Hong Kong Government, 1994.

7. Transport Department with Ove Arup and Partners. Parking Demand Study - Final Report. Traffic and Transport Survey Division, Transport Department, Hong Kong Government, 1995.

8. Town Planning Office, Buildings and Lands Department. Hong Kong Planning Standards and Guidelines. Hong Kong Government, 1989.

9. Transport Department with Wilbur Smith and Associates. Hong Kong Second Comprehensive Transport Study — Final Report. Transport Department, Hong Kong Government, 1989.

10. Stopher P. and Lee-Gosselin M. Understanding Travel Behaviour in an Era of Change. Elsevier, UK, 1997. 